\title{
Design and Fabrication of Friction Stir Welding End-Effector for an ABB IRB1410 Robot
}

\author{
Vanama Santosh, V. Raghavendra Rao, Vasanth Kumar CH \\ Departement of Mechanical Engineering, SRM University
}

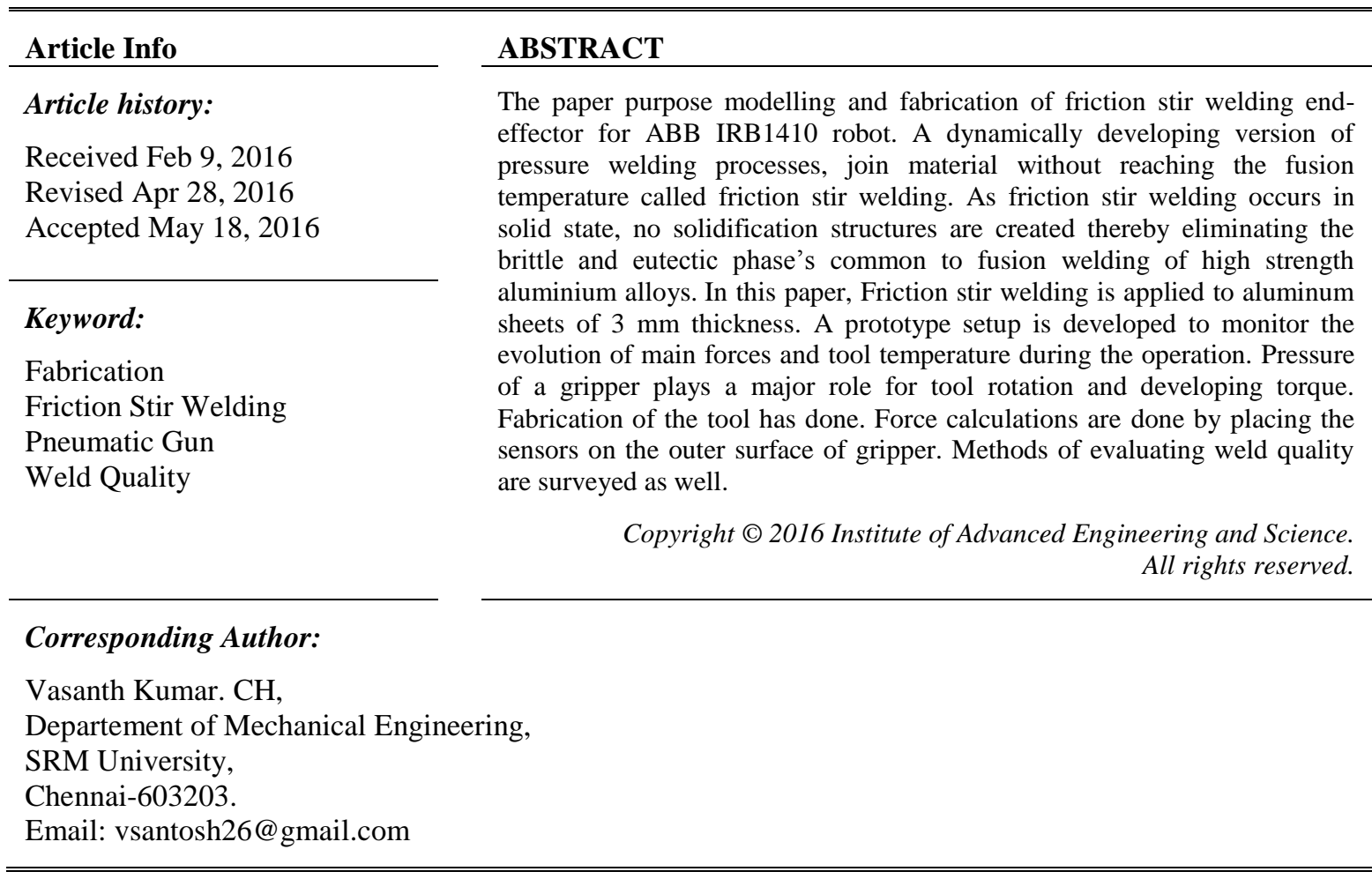

\section{INTRODUCTION}

Friction stir welding (FSW) is a relatively new and processing solid state welding technology developed by The Welding Institute (TWI) of UK in 1991 [1]. Due to its energy efficiency, environment friendliness and versatility, this joining technology has been widely applied in various industrial applications in recent years, such as shipbuilding, railways, automotive and aerospace industries. Compared with conventional fusion welding technologies, FSW is mainly characterized by joining material without reaching the fusion temperature, avoiding the problems caused by melting metals [2]. As a result, almost all types of aluminum alloys, even that are classified as non-weldable by traditional fusion welding techniques, can be welded through FSW process [3].

Industrial robots has been increasingly used in the FSW process to replace commonly-used dedicated machines because of the excellent repeatability, production flexibility and low cost [4]. Smith et al. (2003) [5] developed a FSW system which is integrated to an ABB IRB 7600 articulated robot and the capability of implementing three-dimensional contours welding to various positions with excellent force feedback control was proved. Bres et al. (2010) [6] established a model-based framework which allow the simulation, analysis and optimization of FSW processes of metallic structures using industrial robots.Applied on-line [7] sensing and path compensation methods to obtain a strong and defect-free welding in robotic FSW process. [8] Demonstrated a successful development and evaluation of a closed-loop control system for robotic FSW that control plunge force and tool interface temperature by varying spindle speed and commanded vertical tool position. 


\subsection{Welding Process}

In FSW the part to weld are joined by forcing a rotating tool to penetrate into the joint and moving across the entire joint. The solid-state joining process is promoted by the movement of a non-consumable tool (FSW tool) through the welding joint. It consists mainly in three phases, in which each one can be described as a time period where the welding tool and the workpiece are to move relative to each other. In the first phase, the rotating tool is vertically displacing into the joint line (plunge period). Then period is followed by the dwell period in which the tool is held steady relative to workpiece but still rotating. Owing to the velocity difference between the rotating tool and the stationary workpiece, the mechanical interaction produces heat by the help of frictional work and material plastic deformation. This heat is dissipated to the neighboring material, promoting an increase of temperature and consequent material softening. After this two initial phases the welding operation can be initiated by moving either the tool or the workpiece relative to each other along the joint line. Figure 1 [9] gives a schematic representation of the FSW setup and operation.

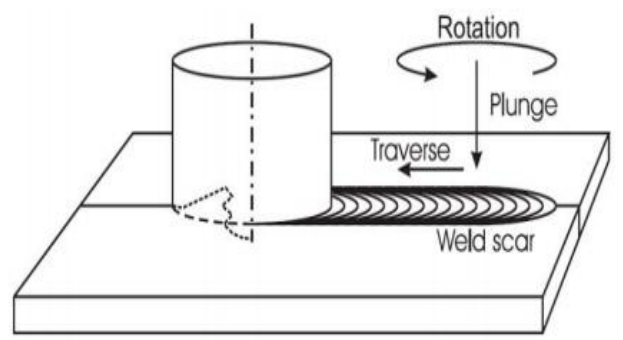

Figure 1. Friction Stir Welding Setup

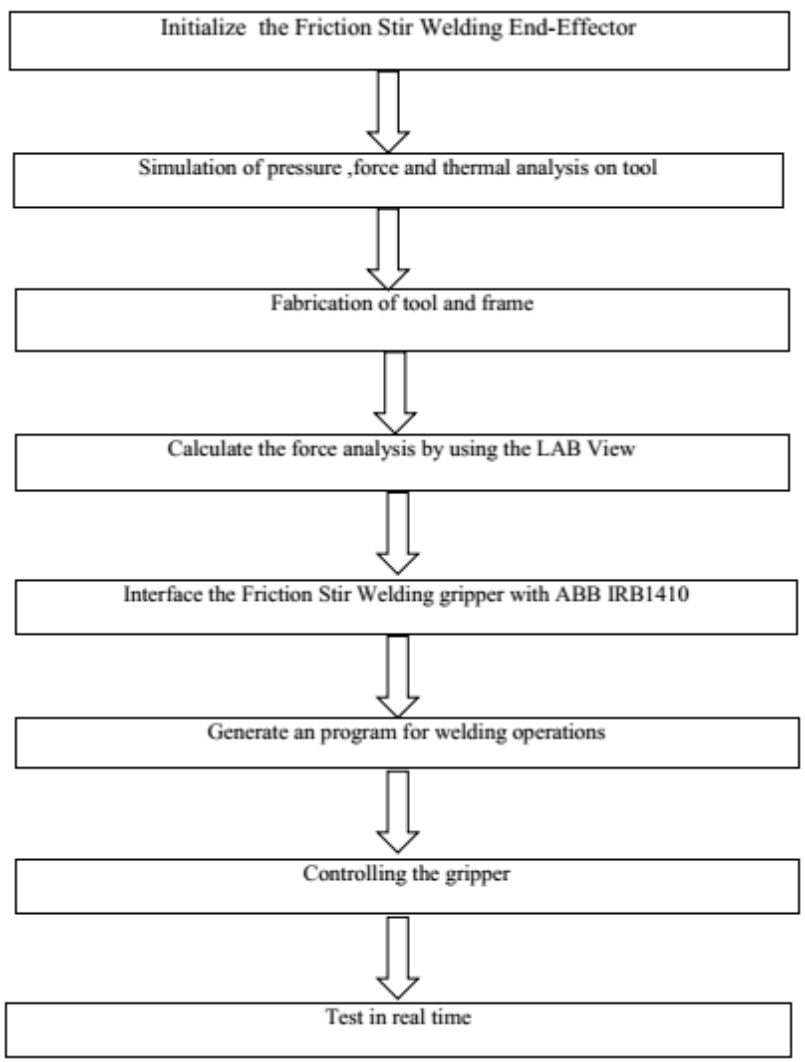

Figure 2. Flow chart of Methodology

These paper is organized as follows: The experimental methodology is introduced in Section 2. In Section 3, the data of design, followed by the fabrication of the tool and frame. Section 4, force analysis by using the LAB View. In Section 5, conclusion and future. Finally, acknowledgement of the paper are given in Section 6.

Design and Fabrication of Friction Stir Welding End-Effector for an ABB IRB1410 ... (Vanama Santosh) 


\section{METHODOLOGY}

The approach towards the making of the end-effector has been split into different steps which goes like designing, fabrication, quality control and controlling of the robot. Figure 2 says the steps of the methodology of project. First step is to initialize and identifying the problem. The second step is developing the concept to overcome the problem which has been identified in the first step. Once the concept is developed for the identified problem, the different possibilities of the concept is sketched out and studied. The optimum solution for the concept is arrived after the studies. The next step is to develop the conceptual idea into a 3 dimensional model using modelling software by SOLIDWORKS. The various calculations are done such as DH parameters. Then analysis of the complex model in order to identify fundamental properties had been carried out. Next stage is to fabricate the weld tool and interface to ABB IRB1410.Then an algorithm and program is to be developed for the ABB Robot for the purpose of friction welding operation by friction stir welding end-effector. in real time.

Finally, the friction stir welding is interfaced with the robot for verifying the algorithm and program

\subsection{Matertial Used}

Various materials where proposed and their properties are studied. Some of the material proposed is as follows: Aluminium alloys, HCC (High Carbon Steel), HSS (High Speed Steel), Chromium.

\section{EXPERIMENTAL SET-UP}

The IRB 1410 gives you fast and reliable work cycles that boost productivity. The robot is proven in arc welding applications and provides outstanding performance and value, ensuring short payback times. The robot has a handling capacity of $5 \mathrm{~kg}$ at the wrist with a unique $18 \mathrm{~kg}$ additional load for applications equipment on the upper $16 \mathrm{arm}$. Superior levels of control and path following accuracy provide excellent work quality. The ability to adjust process speed and position means you achieve optimum manufacturing accuracy with little or no rejects.

IRB 1410 is known for its stiff and robust construction. This translates into low noise levels, long intervals between routine maintenance and long service life. The robot has a large working area and long reach. The compact design, very slim wrist and high performance operation even in difficult and restricted locations.

Easy-to-use all functions is included as standard in the IRC5 robot controller are made available via the patented programming and operation interface unit - the Flex Pendant.

Table 1. Specifications of ABB IRB1410

\begin{tabular}{cc}
\hline Robot & Handling Capacity \\
\hline Supplementaryload & $18 \mathrm{~kg}$ \\
On axis 3 & $19 \mathrm{~kg}$ \\
On axis 1 & \\
Number of axes & 6 \\
Robot manipulator & 6 \\
External devices & 12 signals on upper arm \\
Integrated signal supply & Max .8 bar on upper arm \\
Integrated air supply & Single cabinet, compact \\
IRC5 controller variants & $2.1 \mathrm{~m} / \mathrm{s}$ \\
Max. TCP velocity & 6 \\
Continuous rotation of axis & $225 \mathrm{~kg}$ \\
Weight of robot &
\end{tabular}

\section{DESIGN}

3D modeling software was used to design the model of the friction stir welding. The model will be with a rigid aluminum structure as the body with a HSS tool cover at the bottom and pneumatic gun. Each model of the segment were created separately and assembled. Calculations done to determine the torque required to move these designs by a pneumatic gun.

In this section, it is explained the results of research and at the same time is given the comprehensive discussion. Results can be presented in figures, graphs, tables and others that make the reader understand easily [2], [5]. The discussion can be made in several sub-chapters. 


\subsection{Design of Weld Tool}

The first step of design process is to develop the weld tool for friction welding. Here the pin is threaded with dia. $4 \mathrm{~mm}$ the connecting the shoulder here the dia. $15 \mathrm{~mm}$, with concavity which is shown in Figure 4.

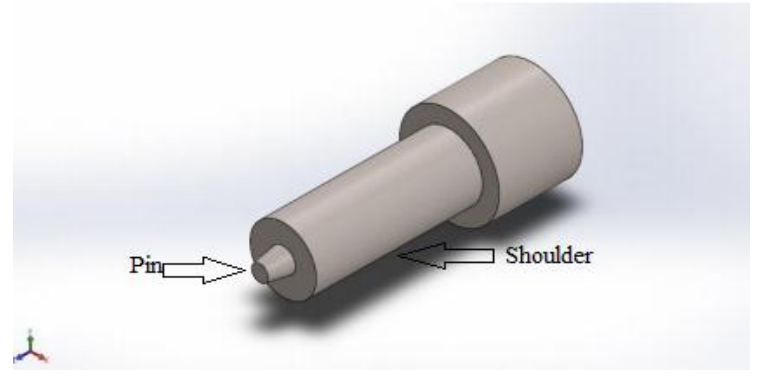

Figure 4. Design of weld tool

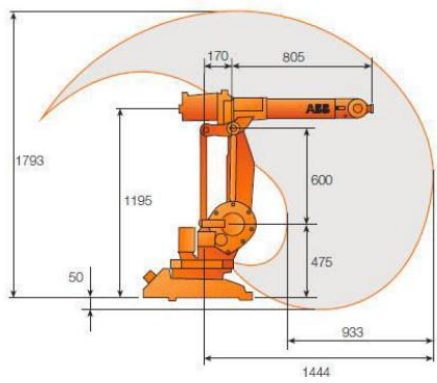

Figure 3. Working range for IRB 1410

The next step of assembly is to mate the base plate to the tool and mounted to the base plate of end effector which has been shown in the Fsigure 5.

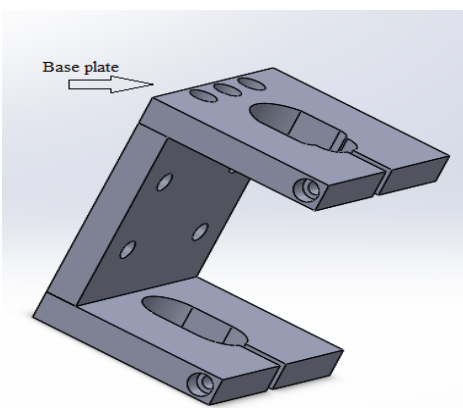

Figure 5. Design of Base Plate

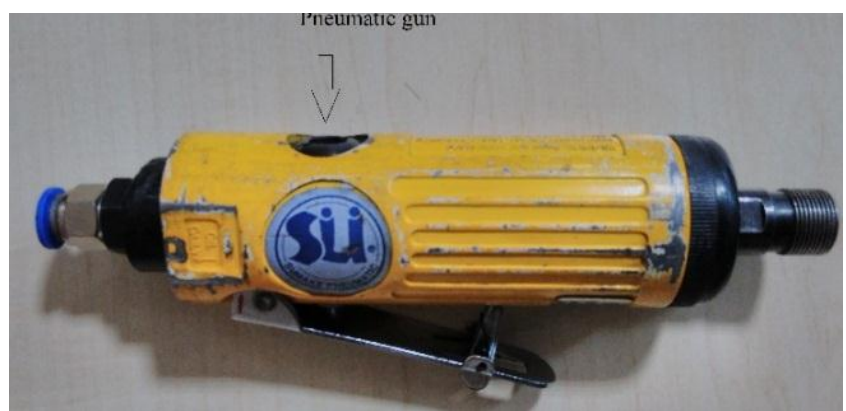

Figure 6. Pneumatic Gun

The next step is to assembly the pneumatic gun with a revolution per minute (RPM) 22,000, torque $2.1 \mathrm{~N}-\mathrm{m}$ which mount the base plate with assembly of tool to the pneumatic gun which is shown in Figure 6 .

\subsection{Fabrication and Mounting to Robot}

The fabrication of weld tool with the HSS material, with the required hardness of material heated up to $900^{\circ} \mathrm{c}$ and quenched in oil as shown in figure 7.

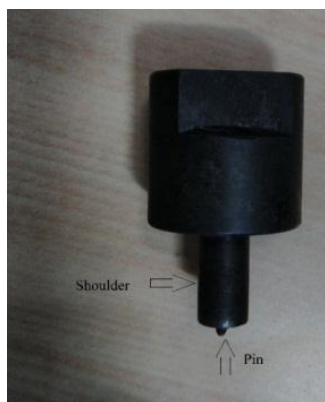

Figure 7. Weld tool

The frame with cast iron material which having a stability to avoid the vibrational feature and to withstand with the robot as seen in figure 8. 


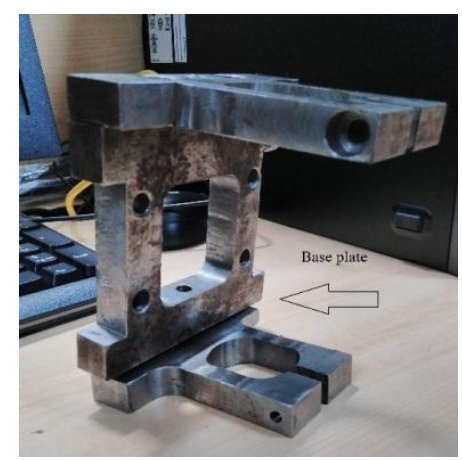

Figure 8. Frame

This robotic welding system is used to implement a FSW operation of some aluminum alloy plates. In this operation, the spindle of the robotic system is controlled to weld in $x$ direction of the tool frame with a constant travel speed $v$ and rotation speed $\omega$. The other welding conditions for the experimental parameters are listed in Table 2.

Table 1. Robotic FSW experimental conditions

\begin{tabular}{lll}
\hline Parameters & Name/Value & Unit \\
\hline Weld Material & AL6082 & \\
FSW tool type & HSS & \\
Material Thickness & 3 & $\mathrm{~mm}$ \\
Torque & 2.1 & $\mathrm{~N}-\mathrm{m}$ \\
Rotational Speed & 12,000 & $\mathrm{rpm}$ \\
\hline
\end{tabular}

The next step is to assembly the tool and frame and the pneumatic gun, to the ABB robot as shown in figure 9.

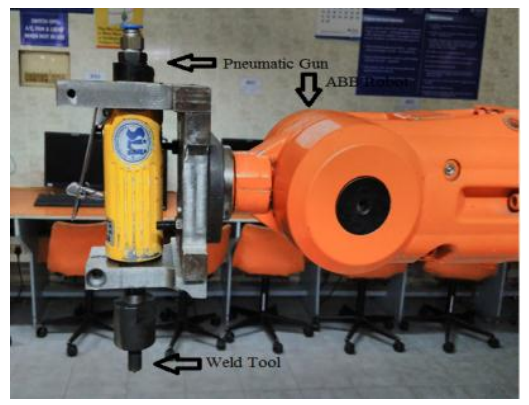

Figure 9. Assembly of setup

The overall view of the setup, mounted to the robot after the fabrication as shown in Figure 10.

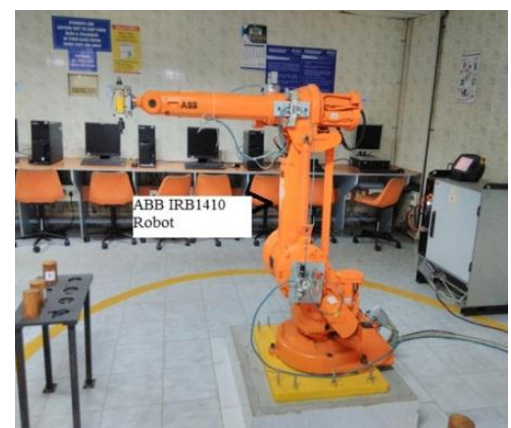

Figure 10. Overall Setup 


\section{FORCE MEASUREMENT}

The force measurement can be detailed by using LABView software by taking the pressure sensor which is mounted to the base plate, the force analysis which shown in Figure 11.

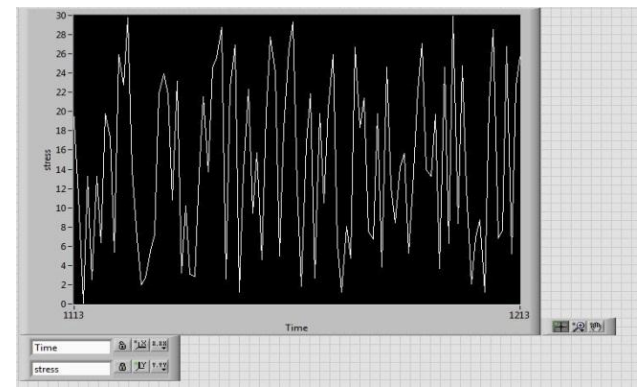

Figure 11. Force Measurement

The next step is the wire diagram of the pressure sensor is been mounted on the baseplate to read the generated pressure and force by the weld tool is shown in Figure 12.

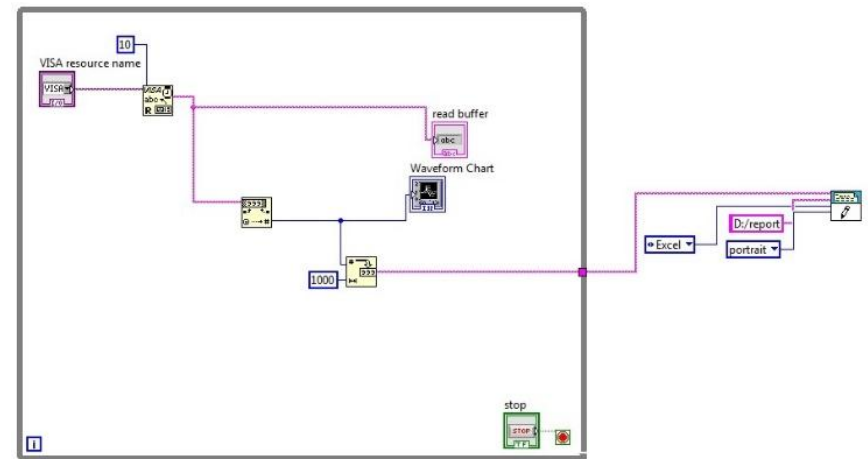

Figure 12. Wire Diagram

\section{RESULTS AND CONCLUSION}

A detailed study over various welding robots has been done. Friction stir welding can adapt to various diametric changes of shoulder and pin diameter weld tool. This friction welding by ABB IRB1410 robot can say the lighter material easily be welded and can be control the RPM of pneumatic gun by flow control valve. This robot can move within it robot work cell with its reachability. Design of weld tool and base plate were done and fabrication has done, trails were made, analysed and rectified for the friction welding. Weld quality test will be carried out as the future work. The experimentations are carried out on the robot to make it efficient enough to move over the material to weld the similar and dissimilar weld plates. Friction weld can be carried out by this robot with a pressure range of 2-5bar. For better welding and larger thickness of work-piece can be weld by other robot like the robot having a high amount of payload. The figure 13 shown below say the welding carried out by using ABB IRB1410.

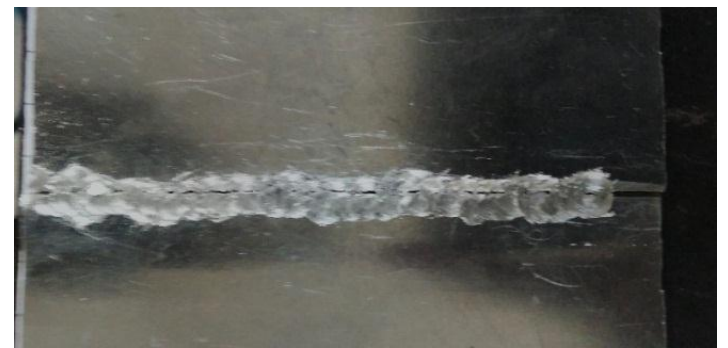

Figure 13. Welded Plates 


\section{ACKNOWLEDGEMENTS}

I feel greatly indebted to my project guide Mr. V. Raghavendra Rao, Mr. Vasanth Kumar.CH and I thank him for the deep interest he has shown in this project and for motivating me to do my best.

\section{REFERENCES}

[1] Thomas, W.M., Nicholas, E.D., Needham, J.C., Murch, M.G., Temple-Smith, P., and Dawes, C.J. (1991). International patent application pct/ gb92/02203 and gb patent application. Technical report, The Welding Institute, London, UK

[2] Mishra, R.S. and Ma, Z.Y. (2005). Friction stir welding and processing. Materials Science and Engineering,Reports, $50,1-78$.

[3] Nandan, R., DebRoy, T., and Bhadeshia, H. (2008). Recent advances in friction-stir welding - process, weldment structure and properties. Progress in Materials Science, 53(6), 980-1023.

[4] Cook, G., Crawford, R., Clark, D., and Strauss, A. (2004). Robotic friction stir welding. Industrial Robot, 31(1), 5563.

[5] Smith, C.B., Hinrichs, J.F., and Crusan, W.A. (2003). Robotic friction stir welding: the state of the art. In 4th Friction Stir Welding International Symposium. Addison-Wesley.

[6] Bres, A., Monsarrat, B., Dubourg, L., Birglen, L., Perron, C., Jahazi, M., and Baron, L. (2010). Simulation of friction stir welding using industrial robots. Industrial Robot: An International Journal, 37(1), 36-50.

[7] De Backer, J., Christiansson, A.K., Oqueka, J., and Bolmsjö, G. (2012). Investigation of path compensation methods for robotic friction stir welding. Industrial Robot, 39(6), 601-608.

[8] Fehrenbacher, A., Smith, C., Duffie, N., Ferrier, N., Pfefferkorn, F., and Zinn, M. (2014). Combined temperature and force control for robotic friction stir welding. Journal of Manufacturing Science and Engineering, Transactions of the ASME, 136(2).

[9] Schmidt H, Hattel J, Wert J (2004), 'An analytical model for the heat generation in friction stir welding', Mo

\section{BIOGRAPHIES OF AUTHORS}
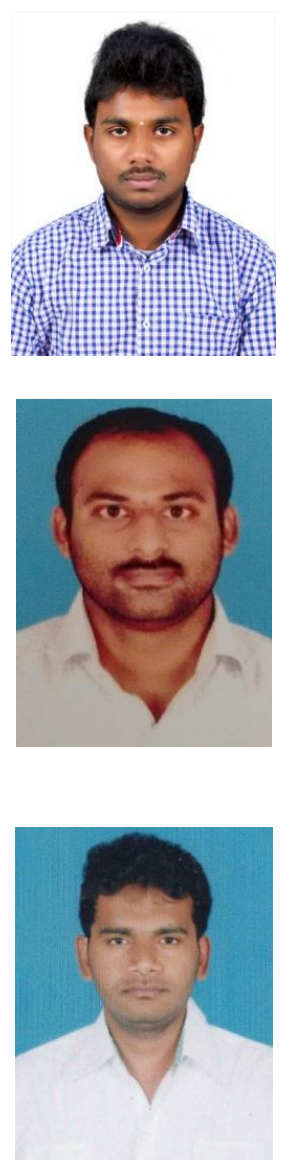

Vanama Santosh a Robotics Engineer done in SRM University in Chennai and Mechanical Engineer done in Guru Nanak Engineering College .Worked in DRDO as JRF for a 6 months of period.
V. .Raghavendra Rao Working as Ass.Prof in mechanical department in SRM University. M.Tech in CAD at SRM University and B.Tech in Mechanical Engineering at Naidu Engineering College. Worked a year in Clarion Power Corporation Ltd, LANCO Group as a Jr.Engineer.
Vasanth Kumar. CH Working as Ass.Prof in mechanical department in SRM University . M.Tech in Robotics at SRM University and B.Tech in Electronics and Instrumenation Engineering at VNR Vignana Jyothi Institute of Engineering and Technology 